\title{
Psicooncología
}

ISSN: $1696-7240$

http://dx.doi.org/10.5209/PSIC.59195

\section{Los demás días (Atención domiciliaria en cuidados paliativos)}

Los demás días. España. 2017. Director Carlos Agulló. Duración 95’. Pendiente de calificación por edades. Película documental sobre los profesionales de cuidados paliativos.

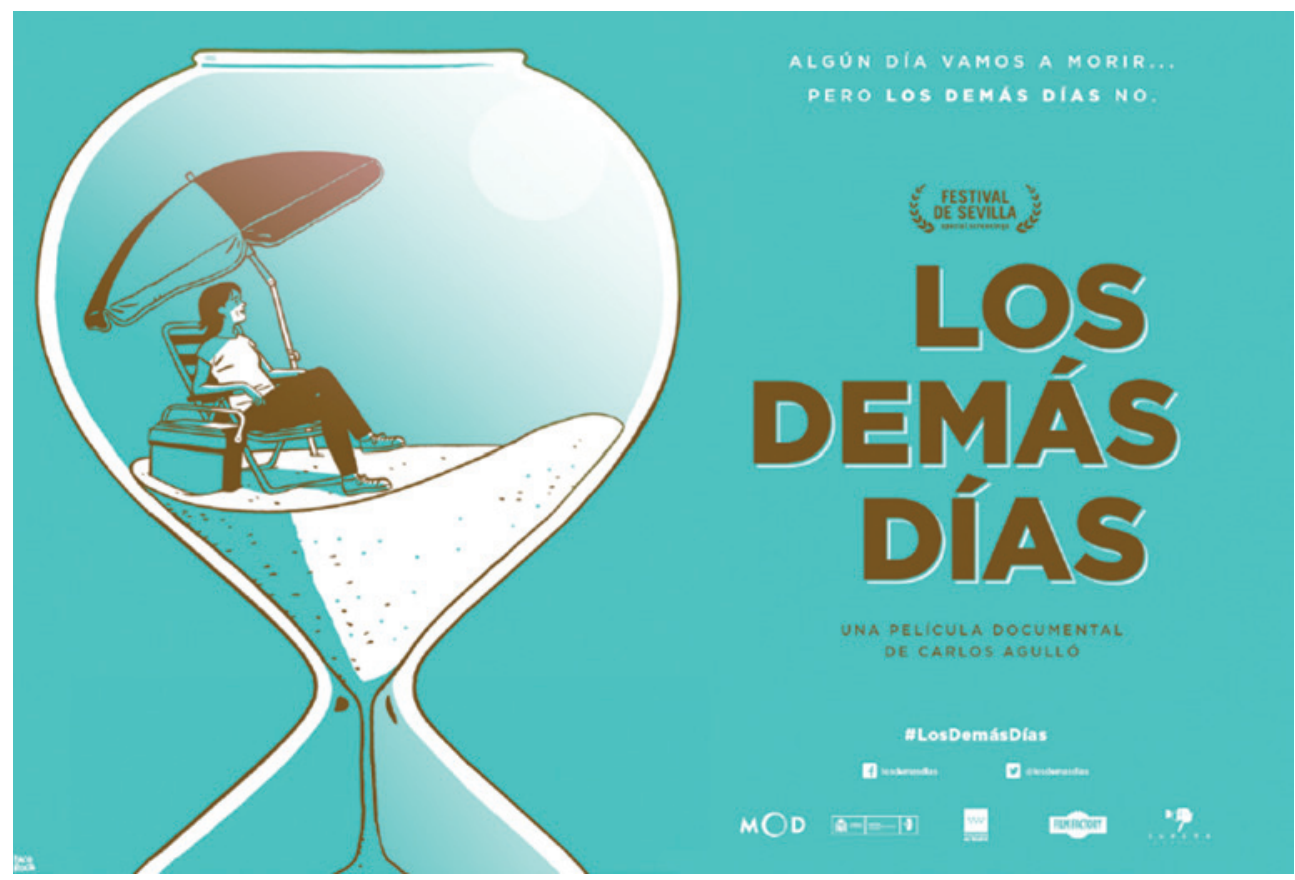

El documental sigue al Dr. Pablo Iglesias, médico de cuidados paliativos. Comparte nombre con otra persona que sale habitualmente en las noticias, pero este médico no es noticia de cabecera de telediario, y a lo mejor personas como él deberían salir más en los telediarios y su labor debería estar más impregnada en la sociedad. Porque lo que se conoce, si además es bueno, da menos miedo. Y dar a conocer lo que se hace en esta área de la medicina y de la salud, haría que cambiaran algunos de los tabús de la sociedad sobre cómo se mueren las personas, y que son, de verdad, los cuidados paliativos. Sin confundirlo con otros conceptos, o con creencias erróneas sobre lo que son los cuidados paliativos (y que no son), que los que estamos familiarizados con este mundo, vemos que sucede a menudo.

El Dr. Pablo Iglesias, es una persona carismática; para las personas que hemos tenido oportunidad de conocerle, aunque sólo sea un poco, podemos decir que es una 
persona que no deja indiferente por su talante, su humanidad, su paciencia, su "saber hacer", su innegable capacidad de conectar con las personas (pacientes y familiares, otros profesionales)...

La idea de este documental le surgió al director cuando la familia le comentó la experiencia con este médico a raíz de la enfermedad paliativa de su suegra. El director conoció al Dr. Iglesias después y se planteó hacer un documental sobre este tema a partir de la figura del médico que tanto había calado a su familia. El director reconoce que el hacer este documental le ha cambiado su concepción de la vida y le ha hecho replantearse muchas cuestiones vitales.

El documental muestra la cara humana de los profesionales, empáticos, el trabajo en equipo, imprescindible, pero también complejo porque hay que conjugar muchos factores y se trabaja con material sumamente frágil. La paciencia, cuando el paciente apenas puede hablar pero necesita ser escuchado, validado, tenido en cuenta en su vulnerabilidad y su percepción de que la vida se acaba. La importancia de la flexibilidad en la atención a la persona, por lo que es, una persona con una trayectoria vital única y distinta de los otros miles de pacientes. Se ve como los profesionales conectan con las personas que se van a morir, pero también conectan consigo mismos para vivir más allá de su trabajo, y tienen ocio y tienen el cariño de otras personas que entienden y conocen su trabajo. Esto es primordial en nuestro trabajo con personas y más en cuidados paliativos.

Se relatan los casos de diversos tipos de pacientes (oncológicos y no oncológicos, ELA,..), diversas edades y situaciones familiares, incluso diversas religiones (por ejemplo, aparece una mujer musulmana como familiar de un paciente, que habla muy poco español pero confía en el equipo médico)

Además se refleja como es la formación a residentes de Medicina de Familia, sobre cuidados paliativos en domicilio, cómo ellos van entendiendo en qué consiste esta tarea de acompañar a la familia cuando no se puede curar. Otro aspecto que muestra la película es la coordinación entre dispositivos hospitalarios y domiciliarios, como el paciente puede pasar de uno a otro, y los sanitarios deben comunicarse entre ellos, para favorecer lo que llamamos "continuidad de cuidados", trabajando en la misma dirección todos los profesionales, y transmitiendo información coherente al paciente y a la familia, sin darle información contradictoria, ni crear falsas expectativas.

Otro aspecto que se ve reflejado, es la labor de la enfermera en el domicilio con el paciente y con la familia, que muchas veces quiere cuidar y está muy dispuesta a aprender, que otras veces se siente sobrepasada y saturada, y que encuentra en el personal de enfermería también una cara, una voz, una persona amiga, comprensiva,

Habla sobre todo de la labor, casi de "encaje de bolillos" de la atención a domicilio, de las llamadas previas a acudir a domicilio del paciente, de los seguimientos telefónicos, de la atención telefónica urgente ante posibles cambios repentinos que se pueden dar en algunos pacientes y la necesidad de solución rápida y del acompañamiento de los profesionales, que tranquilizan, enseñan cuidados y también enseñan a vivir.

En muchas de las proyecciones que se han hecho, también ha habido un coloquio con el propio director tras terminar la proyección; ha habido varias proyecciones en cines convencionales y con profesionales de paliativos en las que el director ha acompañado. También ha despertado el interés de programas de cine consolidados como el programa de la Dos, Versión Española 28 enero 2018. Se destacó la importancia de conectar con la vida, y con las experiencias personales (la presentadora Cayetana Guillén Cuervo, contó su experiencia con cuidados paliativos, cuando su padre requirió de este tipo de cuidados). 
No es una película triste, vemos a los pacientes, ser conscientes de la enfermedad, disfrutar de la vida y reírse (como cualquier persona que no esté enferma), a veces más, porque saben que el tiempo que les queda tienen que aprovecharlo.

La película habla abiertamente de la muerte, desmitifica creencias sociales sobre el final de la vida, porque expresa que los pacientes suelen saber que se mueren cuando están cerca del final y que en un ambiente de confianza lo suelen preguntar abiertamente

Lo que dice el Médico: sobre los cuidados paliativos... "Más que morirse bien es vivir bien hasta el último momento". A un familiar implicado en los cuidados de su ser querido.... "Ojala todos tuviéramos una hija como tú, cuando nos vengan las cosas mal dadas"

Lo que dicen los pacientes entrevistados en la película: "Yo no tengo miedo a morirme porque me siento también en paz" "Por qué tengo que estar luchando todo el día, yo lo que quiero es vivir, no luchar", "siento que mi vida tiene un sentido, quiero seguir viviendo".

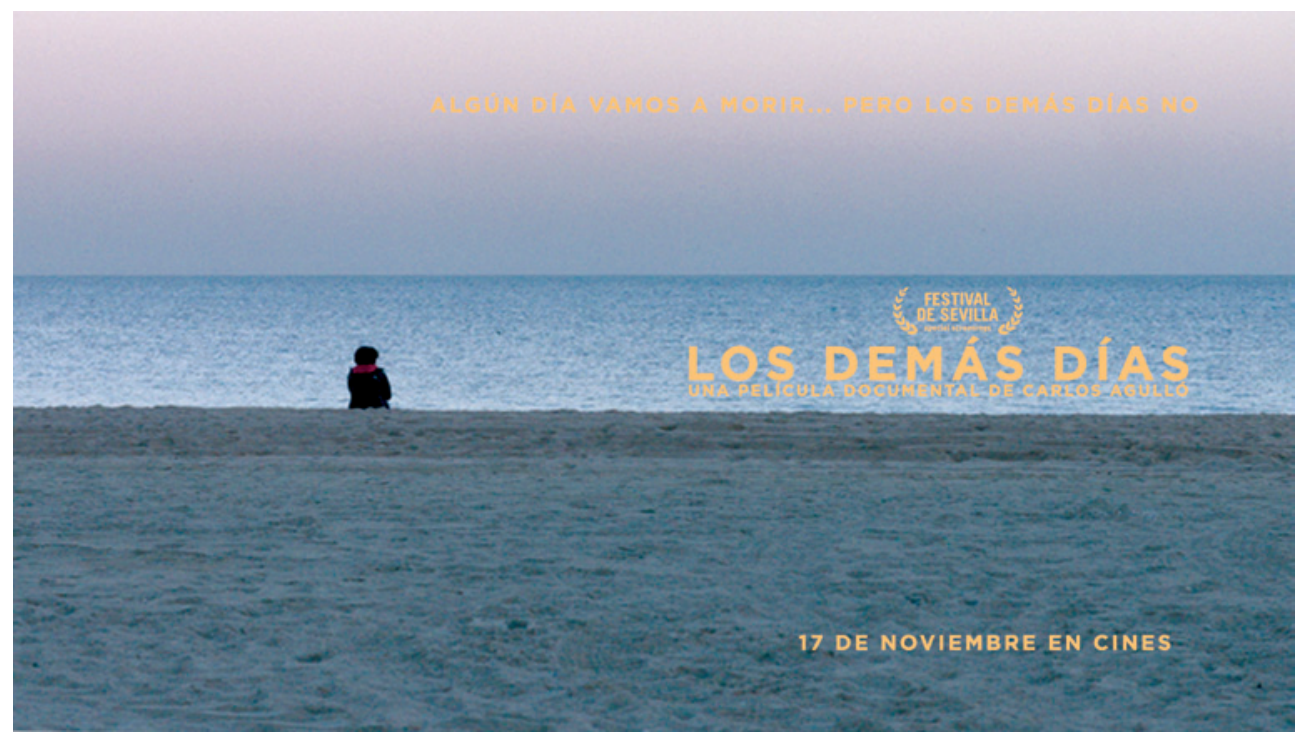

Sinopsis: La lucha por la vida no debe ser un combate contra la muerte, porque tarde o temprano será una batalla perdida. A través del trabajo del Dr. Pablo Iglesias, médico de cuidados paliativos, aprenderemos a ver las cosas de otra manera. No es tanto una cuestión de morir dignamente, sino de vivir bien hasta el último momento. Porque, como la vida vale la pena hasta el último segundo, hay que cuidarla hasta el final Director: Carlos Agulló Reparto: Película Documental Estreno en España: 17 de noviembre de 2017.

Trailer de la película documental (duración1'45") https://www.youtube.com/watch? $\mathrm{v}=$ GMAGVqoti8c 